\title{
University-Industry Technology Transfer: Framework and Constraints
}

\author{
Heqiang Teng \\ School of Management, Xi'an University of Technology, Xi'an 710048, China
}

The research funded by Xian Science and Technology Bureau soft science research funds (SF09018)

\begin{abstract}
Since the 1990s, innovation has been more accepted by many countries as a driver for socioeconomic development. National economic success is ever more determined by a country's effectiveness in mobilizing and utilizing knowledge. Universities are being viewed by policymakers in many countries as engines of growth. This will encourage universities to reconfigure themselves with structures which maximize their capacity for innovation. University-enterprise technology transfer activities are increasingly important as a source of regional economic development and revenue for the university. The conversion of University research into economic growth is vital for the future of the China. In order to improve the efficiency of this transfer, the research should be made know the mechanism and methods for technology transfer between the university and enterprise, The authors develop an overview of the problem and recommend two strategies for accomplishing this end, and presents a technology transfer model seen from the point of view of most technology receivers in Xi'an China.
\end{abstract}

Keywords: Technology transfer, Framework, University-enterprise

\section{Introduction}

It is becoming increasingly apparent that in many countries innovation becomes a central theme of national development. The emergence of innovation-driven economy brings changes in public policy such as public sector reform, education reform, and privatization. This also stimulates increased relationships and interactions among knowledge producers, transfer agents, and knowledge users (Jacob et al., 2003).

Universities have traditionally been thought of as the places for higher education and basic research, but serve increasingly also other than purely public interests. Over the last 25 years, we have seen a significant increase in formal technology transfer from universities and research institutes to private sector organizations in exchange for monetary compensation. It is the Government's expectation that the universities should have a third leg in entrepreneurial activities, in addition to the teaching and research activities. It is hoped that the universities actively push for the commercialization of their inventions through spin-offs, and technology and patent licensing, this also named server society.

Therefore, cooperation between universities and the industry needs to be intensified and university-inventions geared more into innovations, as it is vital that knowledge flows from universities into business and society. Stimulating collaboration between universities and the industry, technology transfer and commercialization of university-born inventions are the pertinent to achieve Vision 2020. It is viewed as an enabler to:(1)gain access to local university resources through consultancy, student projects and joint R\&D projects; (2)foster collaborations in local industries as well as global network (3)nurture science and engineering talents for growth of technology clusters; (4)network industries and professional organizations for exchange and community building.

For technology-based companies, more and more skillful engineering professionals are required to expatriate to foreign technology-advanced companies for technology transfer purpose. And many engineers combined with the university teachers innovations. Past research on the technology transfer mainly focused on factors influenced the results related issues, which are quite different from the problems faced by technology receivers.

To improve the technology transfer performances, nearly a third of the nation's governors have called on legislatures to increase funding for universities technology transfer programs. The paper describe the research objectives firstly in simplest, then provide a brief overview of the general idea of the technology transfer, followed by a description of the research methodology and the mechanism. Then, the document presents a technology transfer model seen from the point of view of most technology receivers in Xi'an China, so as to promote the technology transfer results and improve the economy developing quality.

\section{Definition: university-enterprise technology transfer}

\subsection{Technology Transfer}

Technology transfer is such a concept that is absolutely broader than the acquisition of physical assets. The exchange of technology and know-how between firms, in fact, should contain the exchange of both resources and competence of two organizations (Lynskey, 1999). Lynskey indicates that the nature of knowledge that is, transferability and transparency, involved in technology transfer will become influential factors for success of the process. The transferability of knowledge refers to the extent to which knowledge can be transferred. If the 
knowledge is tacit, it is more difficult to share implicit or to transfer only through coded signs and symbols. Thus, if more tacit knowledge is involved in the technology transfer process, it is apparent that professional expatriates should try to spend more time with the technology group, to understand the norms in their organizations, or even build good relationships with the key persons in the donor firm. The transparency of knowledge is defined as the willingness or openness of a donor firm to release information and to explain difficult issues to the recipient firm. It is apparent that the more openness of the donor firm will be favorable for the transfer of technology. Besides, some superior information or know-how is still conveyed through intensive interactions among people, the process may be iterative, requiring additional interpersonal contact. Thus, some social activities among expatriates and people in donor firms may also be good for fostering favorable relationships and then to facilitate successful technology transfer (Grosse, 1996).

The term "technology transfer," as used here, refers to the process whereby invention or intellectual property from academic research is licensed or conveyed through use rights to a for-profit entity and eventually commercialized. This is a process that takes several steps (Parker and Zilberman, 1993; Parker, Zilberman and Castillo, 1998; and Thursby, Jensen and Thursby, 2000).

\subsection{University-enterprise Technology Transfer}

The rapid rise in university technology transfer and the increased emphasis on transferring technology to the private sector for commercialization as an economic development strategy has led to a number of empirical studies. The initial issued confronted in these studies is how to measure Technology Transfer output. The studies use a variety of measures, including licenses executed, amount of royalties, amount of patents, citation analysis, patent applications, invention disclosures and a six item summary scale. The Data Envelopment Analysis (DEA) by Thursby \& Kemp (2002) has the advantage of estimating productivity scores (distance from the productivity frontier) using multiple outputs. Two studies use survey techniques to ascertain the outputs.

The current emphasis on university Technology Transfer can be dated to the 1980 enactment of The Patent and Trademark Law Amendments Act, P.L. 96-517, more commonly known as the Bayh-Dole Act. Bayh-Dole instituted a uniform patent policy, removed many of the restrictions on university licensing, and allowed universities to own patents arising from federal research grants. The underlying purpose of Bayh-Dole is that inventions resulting from federally funded research should be licensed to industry for commercial development in the public interest.

The growth in the commercial applications of university research has received considerable attention from public officials and university administrators. More and more research universities have set up their institution's Technology Transfer Office (TTO), although the exact name of the office varies among universities.

University administrators cite technology transfer as evidence of the increasing contribution of universities to the economy (more rapid technological diffusion to the public and enhancing local/regional economic development), and recognize it as a potential source of university revenue, especially in the current economic environment of reduced support for universities. Among the other benefits of technology transfer to academic institutions are positive effects on curriculum, and a marketing tool to attract students, faculty and additional industrial research support.

\section{Conceptual Model: The University-Industry Technology Transfer Model}

\subsection{Conceptual Model}

It is recognized that there are several and important technology developments and each day more and more companies are creating and innovating in-house processes, products, knowledge, technologies, which might be transferred either to other companies or to other countries. Nevertheless, we feel that transferring these technologies to the market remains still an opportunity area for many innovation centers and universities.

An description of technology transfer mechanism requires a model of the factors and a system requires a model of the applications it is intended to support. Without a model, it is impossible to determine what variables to measure, what attributes to observe, what data to gather, what questions to ask, what relationships to explore, and what scales of measurement to employ. We put up with a framework of technology transfer based on the relative research results.

The model represents our interpretation of most universities' and industries' reality. At the same time, the model pretends to show opportunities to create a proper technology transfer environment for innovation.

There are many mechanisms for the technology transfer of research and technologies developed by local universities and research institutions. At first this may just involve discussing areas of mutual interest or getting involved in an undergraduate research project or providing a placement for a student to get work experience. The next step is to start larger scale collaborations. This normally involves a contribution from the external partner. The type of technology transfer mechanism to be used in any particular research depends on various factors.

The typical technology transfer model which we think applies for most companies is graphically shown in the next figure 1: 


\subsection{The mechanism of university-enterprise transfer}

\section{1) Market requirements}

As in many technology transfer models, the point of entrance is lead and defined by the Market. The unsatisfied needs represent a lot of opportunities for entrepreneurs and universities. In some cases, those needs could be very basic (e.g. there may be a need for modern and efficient public services), but also, in high technology markets, the needs might be so complex and sophisticated as those the industry has in any developed country.

A good understanding of the market is necessary when somebody is trying to introduce new products or technologies. It is frequent to find business cases which are not based on the reality but they are based on figures and facts in developing countries.

\section{2) "Imaging phase"}

The next step of the model is the "Imaging phase". Here is when a solution and process is developed. In this phase, not only market needs should be considered but also it is important to look at the political and economical environment in order to foresee the actual viability of the product introduction.

\section{3) seeking technology}

Once a solution has been created and documented, starts the seeking of available technologies. A common practice is the creation of joint ventures between university and companies.

A company having the idea and a business case, typically starts to look to universities trying to find available technologies that may satisfy the needs. In those ventures, the university typically provides the technology and "know-how" of the core business while the partner provides the know how on administrative tasks (accounting, human resources, taxes, etc.)

It is important to mention that the circle marked as "available technologies" could be any of the technology transfer models seen in class. We see the enterprise need as input for that technology transfer models where the market is the input.

\section{4) Prouduct design}

One important point to consider is that, a "tropicalization" of the technology is frequently needed. Here we see a very important loop going back and forth until the technology is ready for the enterprise conditions. The chosen technology must be adapted to fulfill not only market needs, but also regulatory aspects such as technical specifications and security norms.

\section{5) Implementations phase}

When the technology is ready, starts the implementations phase. If the technology is a final product, i.e. it goes to a consumer, the implementation phase may be the commercialization and consequently the logistics period for importation, delivery and so on. If the technology to be deployed is part of a manufacturing process or infrastructure of a venture, the implementation phase exactly that, deploying the technology up to the point it is ready to produce the final products. Since this technology is either a final product or part of the production chain of a final needs are being satisfied or a modification is needed. When needs are not being satisfied, a loop back to step 4 should be considered.

\section{6) life cycle management}

The final step in our model is the "life cycle management". Here, we mean that the product, the market, the process should be constantly evaluated. If needed, a loop back to the adaptation step may be considered, but if needs are dramatically changed or if new opportunities are detected, a loop back to start the cycle should be considered. A good opportunity to adapt existing technologies to new processes or products is there available for the implementation step.

\section{Constraints on University-Industry Technology Transfer}

As a developing country, the need for greater university-enterprise collaboration and research commercialization is hampered by a number of constraints including:

the dominance of foreign investments in the critical sectors of manufacturing;

lack of really effective R\&D funding in industry;

the lack of highly capable scientists who can lead in terms of knowledge frontiers,

the lack of innovative entrepreneurship; and

the focus of universities towards teaching thus creating a divergence of objectives between university and industry.

The industrial perspective on working with the universities is that it is difficult to gain the academic's active interest in R\&D activities pertinent and specific industrial problems. The industries are alert of the large amounts of know-how in the universities, but find it difficult and time consuming to extract the details. The scientific knowledge of universities is not something that the companies can receive and utilize right away, but requires 
additional R\&D at the firms, with the assistance of the universities. It also seems that the industries face a short term focus when dealing with the academia.

The local venture capital (VC) industry which is still in its infancy companies, help start-ups by disciplining them to stay focused on delivering their products, providing market access through their knowledge of the business and other investments; and, building the business by means of mentoring and attracting talents. But the local VC industry is not matured enough to provide these sort of support.

There is a road behind. Technology incubators or innovation centers must take advantage of those roads behind us and start from where they are. Technology programs should be focused to satisfy enterprise needs but also global markets. The technology transfer model in which we look for technology outside our boundaries, can not be phased out or replaced from night to day. Instead, we feel that technology incubators should use this model. Probably the first place to attack based on our model, is the "tropicalization". This should be the base to develop new technologies in the short future.

\section{Accelerating University-Industry Technology Transfer towards Commercialization}

Various enhancements are in line with the aim to focus on key and strategic areas of research and to provide adequate funding to research that are in-line with market needs or market-driven R\&D. The commercial viability of the research output has been placed as the key criteria for approval, apart from technical feasibility during the evaluation process.

The realignment of the different $R \& D$ grant schemes in Malaysia has also been orchestrated, aiming towards streamlining the objectives and management of the existing grant schemes under one management body. The previous grant schemes has been realigned and grouped into generation of new knowledge and development of technology for commercialization. The scope of funding has also been expanded to include funding for incubation and pilot plat. The focus here is to generate a smooth flow in the Linear R\&D\&C Value Chain, from basic R\&D work to commercial trials and then to full industrial scale-up.

In addition, government policies have included special tax exemptions for expanding industrial support of Research and Development (R\&D), expanded permissions for collaboration with foreign R\&D supporting institutions, and the development of a strong research infrastructure.

From legal perspective, the situation regarding the ownership of university-inventions has been complex resulting in many arguments, and ultimately difficulties in technology transfer. There is also a serious mismatch between public-funded R\&D and market needs. Most R\&D outputs fail to make it to the market. On top of this, there is poor diffusion of knowledge amongst the main actors of the innovation viz., firms, research institutes, and universities. Since information, knowledge sharing and collaboration are the mainstays of innovation, this issue warrants a serious look.

\section{Conclusion}

University research is a source of significant innovation - generating knowledge, which diffuses to adjacent firms and entrepreneurs. Universities have established technology transfer offices to foster interaction with industry and commercialization of research. Our study advances knowledge about the factors that influence the success of technology transfer and put up the framework of the transfer mechanism, then, also suggests policy recommendations. Among the contributions of the study is to analysis the impact of university organizational practice and environmental factors on the success of university technology transfer.

Despite some drawbacks and constraints with respect to the industry-academia collaboration in the country, the Government over the last fifteen years has been putting into place an integrated Science \& Technology Policy encompassing a number of strategies enabling such an activity to thrive in the country's quest for technological mastery. Under the current thrust of S\&T Policy towards this direction, the academic and corporate society will have to be more sensitive with respect to research collaboration.

\section{References}

Grosse, R. (1996). "International technology transfer in services," Journal of International Business Studies, 1996.27, Pp. 781-800.

Jacob, M., Lundqvist, M., Hellsmark, H. (2003). Entrepreneurial transformations in the Swedish university system: The case of Chalmers University of Technology. Research Policy. 2003.32(9), 1555-1568.

Lynskey, M. J. (1999). "The transfer of resources and competencies for developing technological capabilities The case of Fujitsu-ICL", Technology Analysis \& Strategic Management, 1999.11, Pp.317-336.

Sakib Kusmi. (2007). enhancing technology transfer, through university-industry collaboration, 2007.

Thursby, Jerry, \& Sukanya Kemp. (2002). "Growth and Productive Efficiency of University Intellectual Property Licensing." Research Policy, 2002.31, 109-124. 


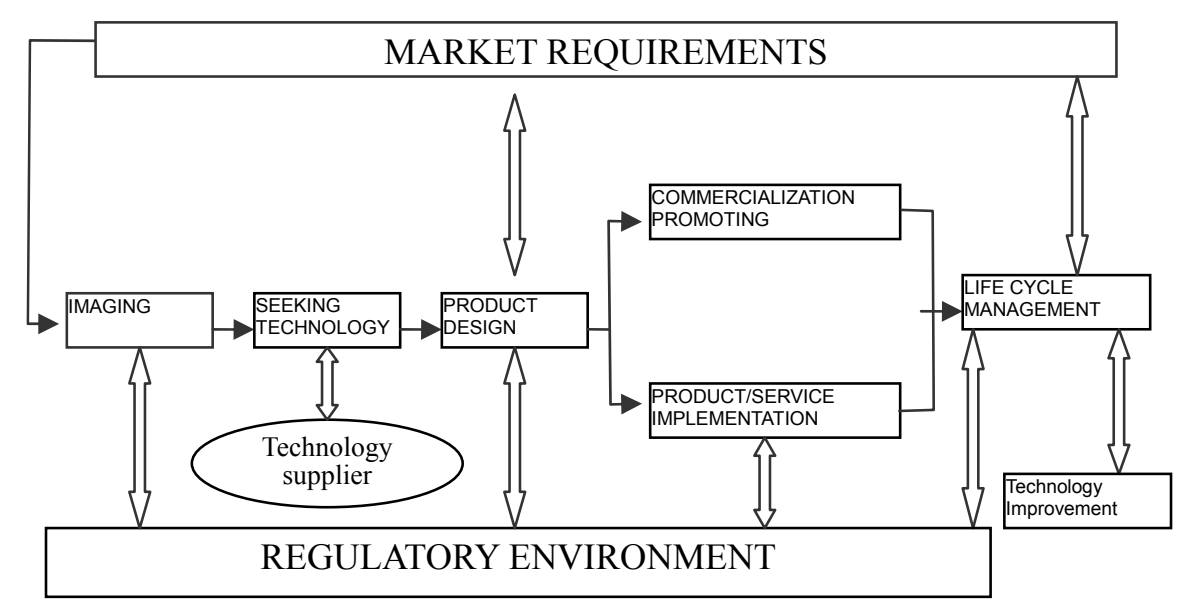

Figure 1. Framework of technology transfer 